\section{P197 EFFICACY OF A LOCAL DOMICILIARY NON-INVASIVE VENTILATION (NIV) SERVICE FOR MOTOR NEURONE DISEASE (MND): PATIENT SURVIVAL, SAFETY AND SATISFACTION}

${ }^{1}$ A Lane, ${ }^{2} \mathrm{~J}$ Tollit, ${ }^{3} \mathrm{R}$ Lewis, ${ }^{1} \mathrm{P}$ Murray. ${ }^{1}$ Ashford \& St. Peter's NHS Foundation Trust, Chertsey, UK; ${ }^{2}$ Respiratory Care Team, Virgin Care, Chertsey, UK; ${ }^{3}$ Woking \& Sam Beare Hospices, Woking, UK

\subsection{6/thoraxjnl-2015-207770.334}

Background NIV is an established treatment for MND patients with ventilatory failure and improves survival by an average of 219 days. ${ }^{1}$ NHS England $(2013)^{2}$ recommend that MND patients are managed by complex weaning and ventilation centres. However, many patients find travel to hospitals difficult and distressing and therefore will not consider NIV. A Domiciliary NIV service was set up in April 2012 to provide integrated care in patients' homes. A small prospective audit was carried out to investigate survival rates, adverse events and satisfaction with the service.

Method Data were collected prospectively from 18 consecutive patients between April 2012 and June 2015 (169 weeks). NIV was started on onset of reported symptoms. All assessments, titration onto NIV and treatment was carried out in patients' homes.

Results 12 of $16(75 \%)$ patients returned satisfaction questionnaires. 8 of $12(67 \%)$ scored the service 10 (highly recommended) on the visual analogue scale, 4 patients left this blank. $100 \%$ responded that they had confidence and trust in the team and preferred to be seen at home. No adverse events were reported by these patients.

Discussion NIV survival with home based care is comparable with the current literature. Of the patients who died, the longest survival was 339 days, 60 days under median survival for those still alive. The reason for this is unclear but may be partly explained by 3 patients with bulbar involvement in this group. Further investigation into this cohort may reveal differences, such as long term feeding. Analysis is required to establish if home care is cost effective.

\begin{tabular}{|c|c|c|c|}
\hline & $\begin{array}{l}\text { All patients } \\
\mathrm{n}=18\end{array}$ & $\begin{array}{l}\text { Still receiving NIV } \\
\mathrm{n}=8\end{array}$ & Died $n=1$ \\
\hline Diagnosis to NIV (days) & 359 (30-2076) & 376 (134-1448) & 359 (30-2076) \\
\hline $\begin{array}{l}\text { Survival from NIV } \\
\text { initiation (days) }\end{array}$ & $181(66-1004)$ & $399(66-1004)$ & $184(90-339)$ \\
\hline $\begin{array}{l}\text { Survival from diagnosis } \\
\text { (days) }\end{array}$ & $690(142-2413)$ & $711(224-2413)$ & $652(142-2572)$ \\
\hline
\end{tabular}

Conclusion MND patients requiring NIV can be safely and effectively managed in a home setting and find this preferable to hospital care. This patient centred model could increase the number of patients offered NIV, subsequently improving uptake.

\section{REFERENCES}

1 Bourke S, Tomlinson M, Williams TL, et al. Effects of non-invasive ventilation on survival and quality of life in patients with amyotrophic lateral sclerosis: a randomised controlled trial. Lancet Neurol. 2006;5:140-47

2 NHS England. NHS standard contract for respiratory: Complex home ventilation adult. Service specification A14/S/a, 2013

\section{P198 MANAGING VENTILATORY FAILURE IN PATIENTS ON LTOT: A CASE SERIES OF OUTCOMES USING NIV}

${ }^{1} \mathrm{~K}$ Hambleton, ${ }^{2} \mathrm{~J}$ Turner-Wilson, ${ }^{2} \mathrm{~J}$ Riley, ${ }^{2} \mathrm{~J}$ Young, ${ }^{2} \mathrm{~N}$ Gabriel, ${ }^{2} \mathrm{~A}$ Nickol, ${ }^{1} \mathrm{M}$ Bafadhel, ${ }^{2} \mathrm{M}$ Hardinge. ${ }^{1}$ Nuffield Department of Clinical Medicine, University of Oxford, Oxford, UK; ${ }^{2}$ Oxford Centre for Respiratory Medicine, Churchill Hospital, Oxford, UK

\subsection{6/thoraxjnl-2015-207770.335}

Background Long term Oxygen therapy (LTOT) has been shown to have survival benefits in patients with COPD when therapeutic levels are achieved $\left(\mathrm{PO}_{2}>8.0 \mathrm{kPa}\right.$, saturations $\left.>92 \%\right)$. But for some patients, loss of hypoxic ventilatory drive, can lead to development of worsening ventilatory failure and symptomatic hypercapnia during oxygen titration. Current guidelines recommend use of nocturnal NIV in conjunction with LTOT in clinically stable patients who develop a respiratory acidosis and/or a rise in $\mathrm{PaCO}_{2}$ by $>1 \mathrm{kPa}(7.5 \mathrm{mmHg})$ during an LTOT assessment on two repeated occasions, but the evidence for this approach is lacking. We present a case series of patients on LTOT who were commenced on NIV for this indication, and look at arterial blood gas outcomes, survival time and hospital admissions.

Methods Patients on both LTOT and NIV were identified using our local database and medical notes were reviewed. Results were analysed using a paired T-test and expressed as means with standard deviations.

Results A case series of 15 patients with COPD on LTOT and NIV were identified. The mean (range) age was 68 (53-83) and mean $\mathrm{FEV}_{1} \%$ predicted was $29 \%$. Mean (SD) pre-treatment $\mathrm{pH}$ on LTOT was $7.36( \pm 0.67)$ and post treatment with NIV $\mathrm{pH}$ $7.41( \pm 0.38), \mathrm{p}=0.089$. Mean LTOT $\mathrm{pCO}_{2}$ was $8.09 \mathrm{kPa}$ $( \pm 1.25)$, and post LTOT/NIV treatment levels dropped to 7.03 $\mathrm{kPa}( \pm 0.85), \mathrm{p}=0.001$; with a significant improvement in $\mathrm{PO}_{2}$ from $7.26 \mathrm{kPa}( \pm 0.64)$ to $8.87 \mathrm{kPa}( \pm 1.15) \mathrm{p}<0.005 . \mathrm{PaO}_{2}$ increased to therapeutic range $(\geq 8.0 \mathrm{kPa})$ in $80 \%$ of patients after commencing NIV with LTOT.

Mean (SD) number of hospital admissions in the 12 months before and after the introduction of LTOT/NIV significantly reduced from $0.87( \pm 0.74)$ to $0.27( \pm 0.59), p=0.023$ (Figure 1). In patients with COPD, the mean survival time from starting NIV in addition to LTOT was 30 months.

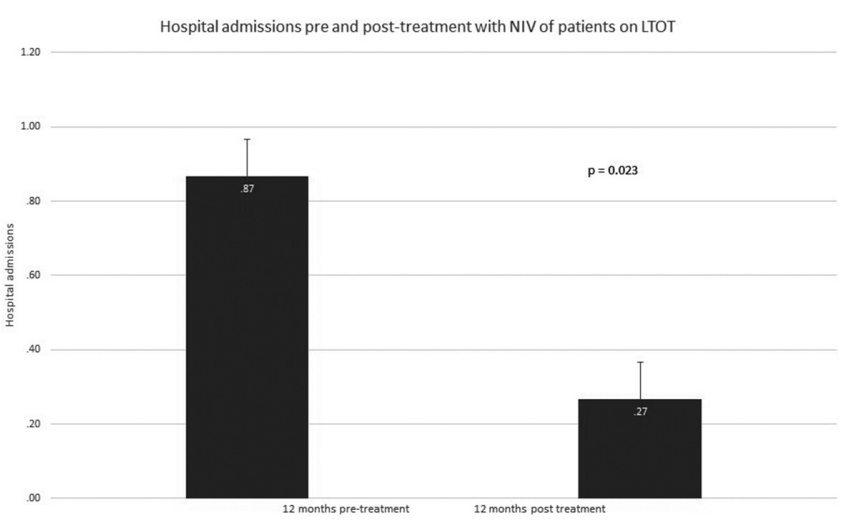

Abstract P198 Figure 1

Conclusion The addition of NIV to LTOT therapy can facilitate therapeutic oxygen delivery, whilst managing hypercapnia. Concurrent NIV and LTOT use can also reduce hospital admissions and increase survival times. 


\section{P199 DOES AVERAGE VOLUME ASSURED PRESSURE SUPPORT (AVAPS) VENTILATION IMPROVE SAFETY IN MOTOR NEURONE DISEASE?}

TS Buttle, S Nathoo, J Kindred, S Banerjee. Medway Maritime Hospital, Gillingham, UK

\subsection{6/thoraxjnl-2015-207770.336}

Average volume-assured pressure support (AVAPS) is a novel way to deliver NIV. In this mode, a target tidal volume is set, and the device adjusts the pressure support to reach that volume. A particular potential benefit is that it may adapt to disease progression, as in patients with progressive Motor Neurone Disease. NICE guidance (2010) recommend follow up every 3 months. We propose to investigate if this new technology improves safety during the initial period of ventilator support.

Aim

1. To identify the trend in pressure support and hours of use of AVAPS ventilation in patients with ventilatory failure due to MND.

2. Look at compliance and tolerability on patients with AVAPS.

Methods Retrospective review of case notes and downloads from the ventilators of 6 patients identified to have started on AVAPS due to ventilatory failure secondary to MND. Average AHI, IPAP, EPAP, hours of use, compliance during first three months were reviewed.

Results There was no significant change in IPAP (Mean 14.78 at 1 month, 14.98 at 3 months) or EPAP (5.91 at 1 month, 6.57 at 3 months). Average use (6 hrs $44 \mathrm{~min}$ at one month rising to 8 hrs $48 \mathrm{~min}$ at three months) and compliance (percent greater than $4 \mathrm{~h} 77.6 \%$ at 1 month to $89.5 \%$ at 3 months) did show positive trends but did not reach significance.

\begin{tabular}{lll} 
Abstract P199 Table 1 & Summary of NIV usage & \\
\hline N & Month 1 & Month 3 \\
AHI & 6 & 6 \\
IPAP & 6.98 & 4.8 \\
EPAP & 14.78 & 14.98 \\
Avg use & 5.91 & 6.57 \\
Avg hrs when using & $06: 44$ & $08: 30$ \\
\% $>$ 4hrs & $06: 44$ & $08: 48$ \\
\hline
\end{tabular}

Conclusions This study shows an increase in average hours of use and compliance in the first 3 months of use. Tidal volumes and pressure support remain preserved. This initial data would suggest no benefit in providing the more expensive AVAPS machine compared to standard BiPAP S/T mode. Larger prospective studies looking at disease progression and ventilation usage in MND are warranted.

\section{P200 DOMICILIARY NOCTURNAL NIV IN COPD - STILL CONTROVERSIAL?}

J Barnacle, CME Longley, V Padmanaban, S Elkin, SAA Bloch. Imperial College Healthcare NHS Trust, London, UK

10.1136/thoraxjn-2015-207770.337
Introduction Despite strong evidence for the use of Non-invasive ventilation (NIV) in acute exacerbations of COPD resulting in decompensated type 2 respiratory failure (T2RF), the evidence for the long-term use of nocturnal NIV to prevent readmission or improve survival is controversial and has often been contradictory. Therefore clinicians are faced with the difficult question of what to do with COPD patients who are admitted with severe exacerbations requiring NIV and are considered at high risk of future decompensation. We hypothesised that domiciliary nocturnal NIV, established following an acute admission with decompensated T2RF delayed readmission.

Methods We performed a retrospective case note analysis of patients started on domiciliary NIV following acute admission to a busy central London acute trust. Indication for NIV and success of treatment were assessed. Time between admissions prior to establishing domiciliary NIV and time to $1^{\text {st }}$ readmission were compared.

Results 18 patients were identified from our database. (2 were excluded: 1 returned their machine immediately, the other never attended for any follow-up at our hospital.) To our knowledge the patients were not admitted to other hospitals in the year pre or post the index admission - the admission at which NIV was initiated. The mean age of the 16 remaining patients was $70 \pm$ 12 years; 9 were female, 8 male. Indication for NIV in 13 patients was COPD with resistant or recurrent T2RF, 1 had COPD plus sarcoidosis and the remaining 2 had COPD plus obesity hypoventilation. NIV was shown to be successful in reducing $\mathrm{pCO}_{2}$ between discharge and first follow up (mean reduction $0.84 \pm 1.17 \mathrm{kPa} \mathrm{p}=0.01$ ). There was a trend towards delayed $1^{\text {st }}$ readmission following initiation of NIV, when compared to the time between previous admission (Kaplan-meier survival analysis. $\mathrm{p}=0.09$ Figure 1).

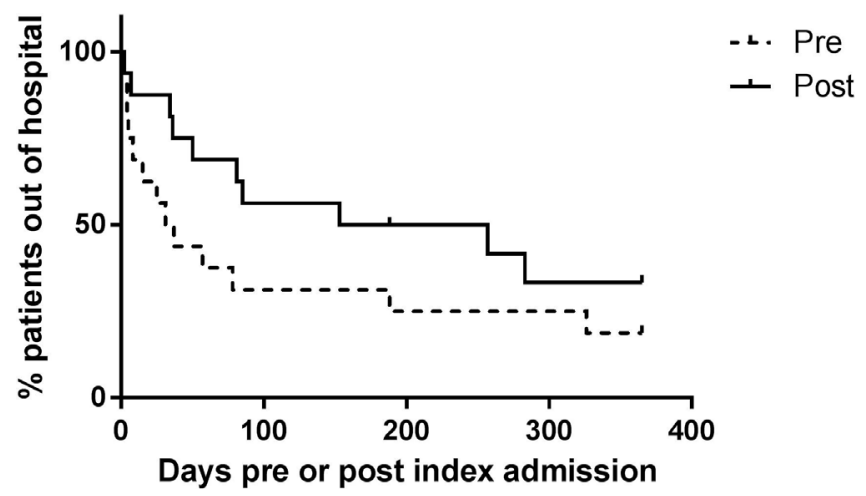

Abstract P200 Figure 1 Kaplan-meier curves of time pre or post index admission for patients $(n=16)$ started on domiciliary. Non-invasive ventilation (NIV) following acute admission with decompensated type 2 respiratory failure secondary to COPD. Difference between the curves suggests a trend towards delayed admission with initiation domiciliary NIV $p=0.09$

Conclusion Domiciliary NIV for high risk patients with decompensated T2RF in COPD is often used because of concerns of leaving the condition untreated when objectively NIV improved the patient's $\mathrm{pCO}_{2}$ furthermore there are no consistently ratified guidelines. The data presented here suggest that NIV may help to delay readmission to hospital. The results of ongoing randomised trials are eagerly awaited. 